\title{
Age and growth of four spot megrim (Lepidorhombus boscii) in northern Iberian waters corroborated by cohort tracking
}

\author{
Jorge Landa ${ }^{a, *}$, Jorge Fontenla ${ }^{b}$ \\ a Instituto Español de Oceanografía, Centro Oceanográfico de Santander, Promontorio San Martín, s/n, 39004, Santander, Spain \\ ${ }^{\mathrm{b}}$ Instituto Español de Oceanografia, Centro Oceanográfico de Vigo, Subida a Radio Faro, 50, 36390, Vigo, Spain
}

\section{A R T I C L E I N F O}

\section{Article history:}

Received 19 December 2014

Received in revised form

29 December 2015

Accepted 5 January 2016

Available online 13 January 2016

\section{Keywords:}

Four-spot megrim

Lepidorhombus boscii

Bay of Biscay

Shelf

Growth

Otolith

\begin{abstract}
A B S T R A C T
Age and growth are key biological aspects for the age-structured assessment of exploited fish populations. Confirming the consistency of fish age interpretation by validation/corroboration studies is essential for providing accurate age estimates to the stock assessment process. The Atlantic Iberian stock of four-spot-megrim (Lepidorhombus boscii), an important exploited demersal fish, is annually assessed by age-structured models in ICES, and specimens are routinely aged by IEO expert readers for this purpose. A total of 11,741 otoliths of this stock were aged from 23 annual groundfish surveys carried out in Cantabrian Sea and Galician waters (ICES Div. VIIIc, IXa) and following internationally standardized protocols. Annual age-length-keys were built using the respective age estimates and applied to the length distribution of each survey, thus obtaining a matrix of abundance indices by age and year. Similar mean lengths are obtained for each age group along most of the time-series. The von Bertalanffy growth parameters for the time-series are estimated $\left(L_{\infty}: 49.0 ; \mathrm{k}: 0.13 ; \mathrm{t}_{0}:-1.13\right)$ and the results are compared with previous studies. The annual growth pattern estimated for $L$. boscii is here corroborated by tracking cohort abundance indices in the surveys. The current otolith age estimation criterion used and the resulting age estimates obtained by the age readers can be considered valid. Strong and weak cohorts are well tracked along most of their age classes, and the correlations between age abundance indices are statistically significant up to the age 6 , which represent around $95 \%$ of the total number of this species caught in the surveys. The findings here presented on the age of $L$. boscii and its corroboration can help to reduce the uncertainty in the estimation of its demographic structure and hence, ultimately, it will be important for a better understanding of its relevance in the functioning of the benthic community of the shelf.
\end{abstract}

(c) 2016 Elsevier Ltd. All rights reserved.

\section{Introduction}

The four spot megrim, (Lepidorhombus boscii) is a flatfish, a common component of benthic fauna found from $100 \mathrm{~m}$ to $450 \mathrm{~m}$ depth, from the British Isles to Cape Bojador and in the Mediterranean (Sánchez et al., 1998; Whitehead et al., 1986). It is captured by mixed bottom trawl fisheries mainly as a bycatch, together with other "white fish" (megrim, hake, monkfish, etc) in European Atlantic waters. Three stocks of Lepidorhombus are distinguished by ICES (International Council for the Exploration of the Sea) and, for L. boscii, the Atlantic Iberian stock (ICES Divisions VIIIc and IXa) is the only one annually assessed. This species is captured in the

\footnotetext{
* Corresponding author.

E-mail address: jorge.landa@st.ieo.es (J. Landa).
}

Iberian stock by the Spanish and Portuguese fleets, with mean annual landings of around $1100 \mathrm{t}$ in the period 2008-2012 (ICES, 2013a).

It is important to take into account that the populations are agestructured because several key parameters (growth, fecundity and survival rates) that determine how the size and biomass of the populations change through time differ noticeably among age groups (Panfili et al., 2002). The use of age-based data is considered to be essential for the understanding of important processes regulating the recruitment of marine fish populations. Age and growth information can provide insights into how a species interacts with its environment (Haddon, 2001) and they are key biological aspects for the assessment of exploited fish populations. Many stocks in the developed world fisheries are assessed by age structured population models (Panfili et al., 2002). A comprehensive knowledge of the age of a population also contributes to more 